\title{
Presence of specific symbiotic bacteria in flies of the subfamily Tephritinae (Diptera Tephritidae) and their phylogenetic relationships: proposal of 'Candidatus Stammerula tephritidis'
}

Correspondence
Vincenzo Girolami
vincenzo.girolami@unipd.it

\author{
Luca Mazzon, ${ }^{1}$ Alessia Piscedda, ${ }^{1}$ Mauro Simonato, ${ }^{1}$ \\ Isabel Martinez-Sañudo, ${ }^{1}$ Andrea Squartini ${ }^{2}$ and Vincenzo Girolami ${ }^{1}$
${ }^{1}$ Dipartimento di Agronomia Ambientale e Produzioni Vegetali, Università di Padova, Agripolis, viale dell'Università 16, 35020 Legnaro, Padova, Italy \\ ${ }^{2}$ Dipartimento di Biotecnologie Agrarie, Università di Padova, Agripolis, viale dell'Università 16, \\ 35020 Legnaro, Padova, Italy
}

\begin{abstract}
The presence of symbiotic bacteria in flies belonging to the subfamily Tephritinae, which predominantly infest the flower heads of composite flowers (Asteraceae), was investigated. Twenty-five species of flies, collected mainly in northern Italy, were examined. The bacteria adhered to the midgut epithelium in a space external to the peritrophic membrane and therefore not in direct contact with the gut contents. Specific, unique and live, but unculturable bacteria were consistently found in the majority of the fly species and their presence was also shown to be persistent in flies reared under microbiologically controlled conditions and devoid of any residual culturable intestinal bacteria. Sequencing of the small subunit rRNA gene from the novel bacteria indicated that they belonged to the family Enterobacteriaceae. Three main strongly supported clades were delineated by phylogenetic trees, the first of which featured a coherent set of sequences displaying gene sequence similarities lower than $96 \%$ compared with recognized taxa. The second and third clades featured cases with higher gene sequence similarities to culturable bacteria, including Erwinia persicina and Ewingella americana, respectively. Relative rate tests were supportive of a fast genetic evolution for the majority of the bacterial symbionts of the subfamily Tephritinae. In agreement with the interpretation suggested in 1929 after pioneering observations made by $\mathrm{H}$. J. Stammer, a symbiotic relationship between the novel bacteria and the tephritid flies is postulated. The origin of this apparently polyphyletic relationship is discussed and a novel candidate organism is proposed for the first clade under the designation 'Candidatus Stammerula tephritidis'.
\end{abstract}

\section{INTRODUCTION}

Several kinds of associations between micro-organisms and insects are found in nature (Buchner, 1965; Baumann \& Moran, 1997). Stable or obligate relationships and instances of co-evolution with bacteria have been traced for aphids (Baumann et al., 1995), whiteflies (Clark et al., 1992), mealybugs (Munson et al., 1992), plant hoppers (Noda et al., 1995), carpenter ants (Schröder et al., 1996), weevils (Campbell et al., 1992), tsetse flies (Aksoy, 1995), cockroaches and termites (Bandi et al., 1994). Among the benefits for the host, it is hypothesized that there may be a

Abbreviations: $\mathrm{BI}$, Bayesian inference; ML, maximum-likelihood; MP, maximum-parsimony; $\mathrm{NJ}$, neighbour-joining.

The GenBank/EMBL/DDBJ accession numbers for the 16S rRNA gene sequences of 'Candidatus Stammerula tephritidis' are EF469611EF469624. specific nutritional complementation, particularly for those insects living on a markedly imbalanced diet, as in the case for aphids (Rouhbakhsh et al., 1996). In the past, such studies mostly relied upon microscopy to define the morphohistological features of symbiotic organs and describe the bacteria hosted within. Indeed, many insectmicrobe associations were covered in Buchner's renowned treatise (Buchner, 1965). However, as most of the prokaryotic microsymbionts are not culturable ex situ, their characterization and taxonomical placement has had to wait until the advent of biomolecular techniques that have enabled $16 S$ rRNA-based taxonomy via gene amplification and sequencing.

In the case of flies belonging to the family Tephritidae, the olive fly Bactrocera oleae (Rossi) (Subfamily Dacinae), was the first species for which a bacterial symbiosis was described. 
Obligate endosymbionts multiply within a specialized organ in the insect head called the oesophageal bulb. From this organ, the bacteria are discharged into the oesophagus and to the intestine where they are eventually digested (Petri, 1909). Recently the olive fly symbiont has been described and characterized as 'Candidatus Erwinia dacicola' (Capuzzo et al., 2005). Other bacterial associations in tephritid flies have been described by H. J. Stammer (Stammer, 1929) and occur in several genera of the subfamily Tephritinae. In these cases, in adult stages, bacteria are located in the first tract of the midgut in contact with the epithelium but, as later reported by Girolami (1983), outside the peritrophic membrane. The peritrophic membrane, which is present in different insect species, is a membranous film that forms a thin lining layer that surrounds the food bolus and separates it from the delicate midgut epithelium. The oesophageal bulb, with some morphological differences, is also found in the subfamily Tephritinae, but in this case it is devoid of bacteria (Girolami, 1973). As found for B. oleae, females of several species of the subfamily Tephritinae smear the surface of their eggs with bacteria during oviposition in order to ensure the vertical transmission of the bacteria to the progeny. The larval stages of the insects maintain the bacteria in their intestinal caeca (Petri, 1909; Stammer, 1929), presumably in contact with free-living intestinal bacteria.

The subfamily Tephritinae includes about 200 genera worldwide with over 1800 species (Foote et al., 1993). Members of the subfamily Tephritinae use the vegetative and reproductive parts of their host plants; the larvae feed on flower heads and many species induce galls in these plant structures (Headrick \& Goeden, 1998). With few exceptions, they feed solely on plants of the family Asteraceae (Compositae), the daisy family (Zwölfer, 1983; White, 1988; Foote et al., 1993). As the larvae do not develop on fruits, these insects are not regarded as pests of economic importance. Nevertheless, some species may occasionally attack agricultural crops, as in the case of Acanthiophilus helianthi (Rossi) that can be found on sunflowers (Belcari, 1985) and on safflowers (Ricci \& Ciriciofolo, 1983). Some fly species have been tested as possible biological control agents for weeds (Zwölfer, 1983). A comprehensive body of literature on the biology of the subfamily Tephritinae is reviewed by Headrick \& Goeden (1998).

In the present work, biomolecular methods were used to investigate the bacterial symbioses first discovered by Stammer in the subfamily Tephritinae (Stammer, 1929) and reported later by Buchner (1965). The purpose of this work was to investigate the gut symbiotic bacteria in different species of the subfamily Tephritinae, exploring the examples described by Stammer (1929) and extending the analysis to uncover the identities of the symbionts via $16 \mathrm{~S}$ rRNA gene sequencing. This approach enabled the existence of a strict host-symbiont specificity to be verified and the possible phylogenetic relationships occurring among hosted bacteria to be traced.

\section{METHODS}

Origin and identification of biological material. Live specimens encompassing 25 different species of the subfamily Tephritinae were collected from 20 field locations, ranging from central and northern Italy, to Slovenia and Croatia (Fig. 1). When possible, the same insect species was collected in different locations and in different years (Table 1).

The floral heads (capitula) of plants, all belonging to the family Asteraceae and containing their respective host insects, were routinely collected. For those insects that were found in more than one species of the Asteraceae, two or three alternative hosts were sampled. An infield pre-screening of positive samples involved blade sectioning of the inflorescences and inspection for the presence of larvae or pupae.

Capitula containing pupae were subsequently sectioned and pupae were extracted, subjected to surface sterilization and reared in aseptic conditions as described below. The harvested floral heads containing larvae were kept within transparent plastic bags at room temperature in order to allow the larvae to complete their development and to pupate. Adult flies that were occasionally captured in the field, or those that emerged during flower incubation in the plastic bags, were transferred directly into net cages.

Host plant determination was carried out using botanical keys (Pignatti, 1982) and supervised by European flora specialists. The taxonomical identification of the tephritid species was performed on a morphological basis on adult stages using appropriate keys (Hendel, 1927; Séguy, 1934; White, 1988; Merz, 1994). When necessary,

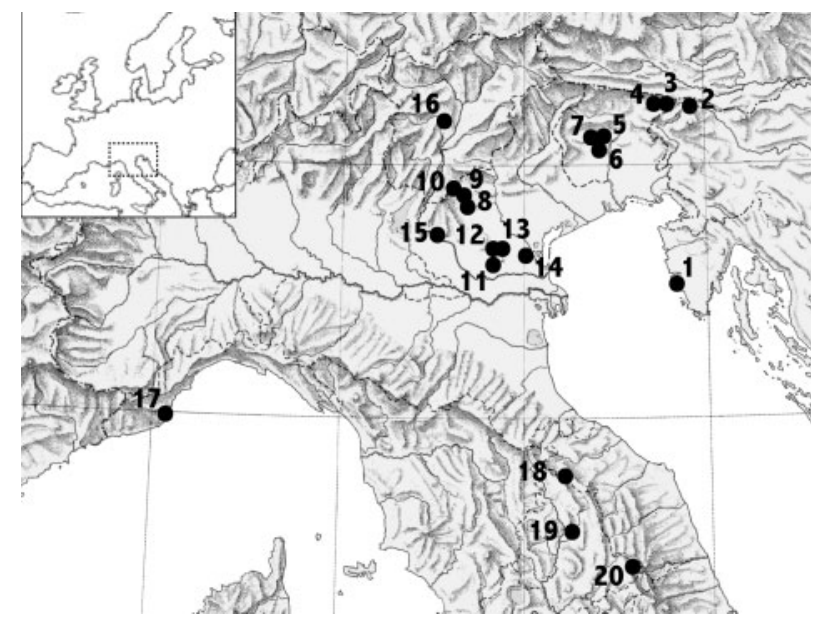

Fig. 1. Insect collection sites. Geographical map of central to northern Italy and surroundings. Numbers refer to the following localities (States or Provinces are indicated in parentheses): 1, Rovigno (Croatia); 2, Kranjska Gora (Slovenia); 3, Tarvisio (Udine, including the sublocalities of $3 \mathrm{a}$ Tarvisio, $3 \mathrm{~b}$ Mount Lussari and $3 \mathrm{c}$ Lake Predil); 4, Malborghetto, Val Saisera (Udine); 5, Fanna (Pordenone); 6, Vivaro (Pordenone); 7, Maniago (Pordenone); 8, Cogollo del Cengio, Mount Cengio (Vicenza); 9, Roana (Vicenza); 10, Asiago, Cima Larici (Vicenza); 11, Cinto Euganeo (Padova); 12, Teolo (Padova); 13, Torreglia (Padova); 14, Legnaro (Padova); 15, Verona (Verona); 16, Tres-Passo Predaia (Trento); 17, Diano Marina (Imperia); 18, Borgo Pace, Bocca Trabaria (PesaroUrbino); 19, Assisi (Perugia); 20, Norcia, Sibillini Mountain Range (Perugia). 
Table 1. Tephritinae species in which symbiotic bacteria have been observed and sequenced

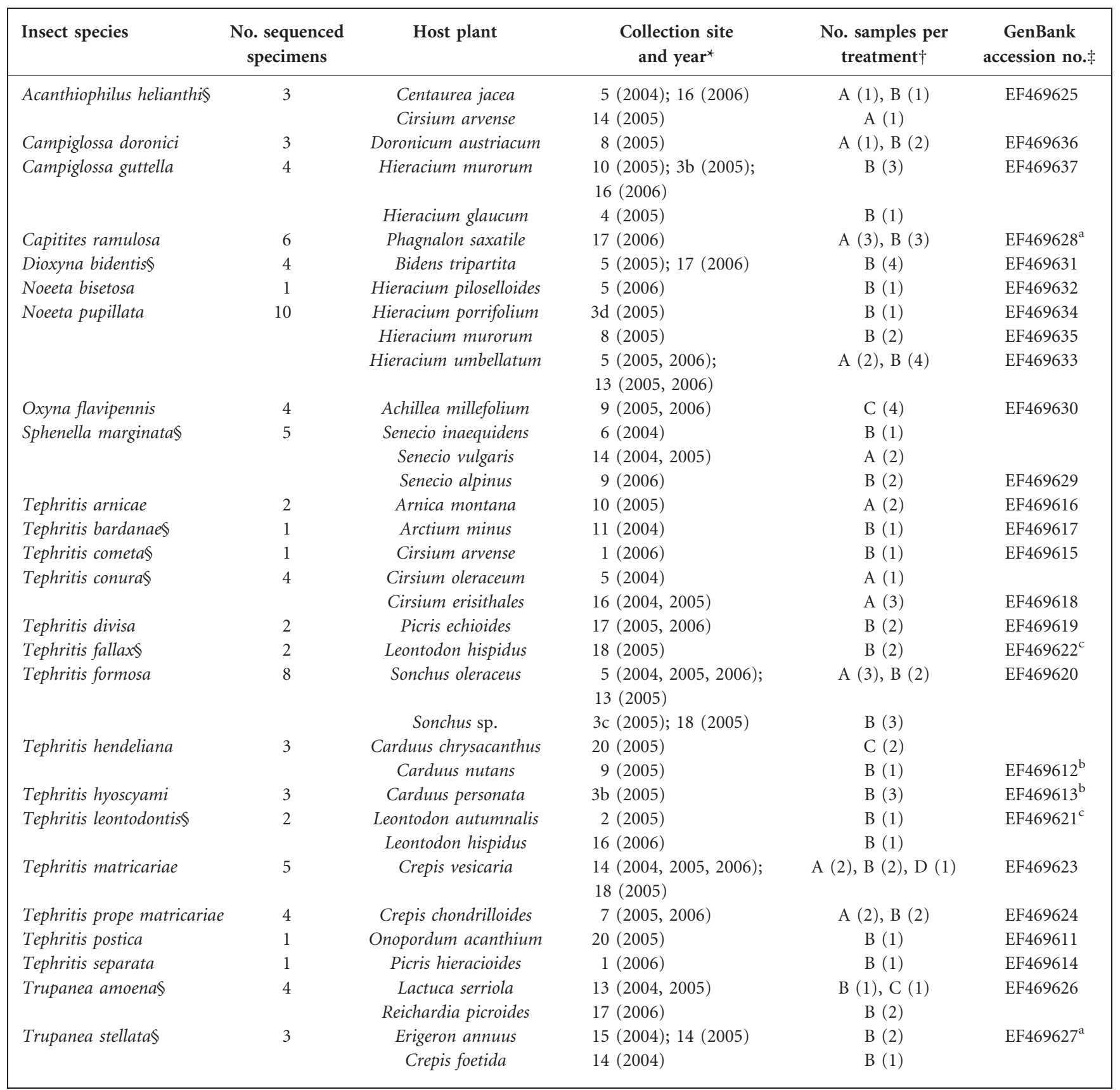

${ }^{\star}$ Numbers refer to collection sites reported in Fig. 1 over the three years.

$\dagger$ Number of sequenced specimens of: A, adults obtained from surface-sterilized pupa incubated in microbiologically controlled conditions; B, adults obtained in non-microbiologically controlled conditions that emerged from flower heads in the laboratory; C, adults captured in the field; D, sequence obtained from surface-disinfected larva.

\$Accession numbers followed by the same letter share an identical 16S rRNA bacterial gene sequence.

$\$$ Species in which the presence of symbiotic bacteria has already been reported by Stammer (1929).

identification was confirmed by the tephritid taxonomy specialist, Dr Bernhard Merz (Museum of Natural History, Geneva, Switzerland).

Insect treatment, rearing and dissection. Pupae extracted from flower capitula were surface-sterilized by a $5 \mathrm{~min}$ immersion in $1 \%$ sodium hypochlorite. They were then rinsed in sterile water at least twice, air-dried in sterile conditions and kept in sterile vials until the emergence of the adults. The resulting flies were kept under microbiologically controlled conditions to avoid contamination with micro-organisms other than the internal bacteria. The flies were then aseptically transferred under a laminar flow hood into larger vials containing a layer of plate count agar (PCA) on the bottom as a 
sterility check and sealed with a sterilized transparent gas-permeable cellulose membrane for dialysis (Sigma-Aldrich). A drop of sterile glucose solution was placed on the internal side of the membrane to allow insect feeding. The drop of solution was rewetted, whenever necessary, by spraying water onto the vials.

When juvenile stages were not found in the field or when it was not possible to remove viable pupae from capitula, adult flies captured from the wild or those that had emerged in the laboratory under nonaseptic conditions were dissected. In these cases, adults were maintained in tulle-lined cages and fed with a $50 \%$ sucrose solution $(\mathrm{w} / \mathrm{v})$ containing $0.2 \%$ benzoic acid and $0.05 \%$ sorbic acid as antimicrobial agents.

After being reared for a week under microbiologically controlled conditions, the flies were dissected for the isolation of bacteria hosted in their midguts. Only specimens from which no microbial colonies had developed on the PCA agar at the bottom of the vials were selected.

Flies were handled under a stereomicroscope in a laminar flow hood using sterile equipment and sterile water. Before dissection, insects were stunned by keeping the vials at $4{ }^{\circ} \mathrm{C}$ for $20 \mathrm{~min}$. The abdomen of the insects was opened and the whole intestine was extracted. The midgut tract was selected from the intestine by sectioning between the cardial valve and the malpighian tubes (Fig. 2). The resulting segment was transferred into a sterile Eppendorf tube and used for both bacterial culturability tests and for bacterial DNA extraction and amplification, in which case the tubes were stored at $-20{ }^{\circ} \mathrm{C}$ until DNA extraction.

Dissection was also performed on adults that had not been reared under microbiologically controlled conditions (either captured from the wild or emerged from the flower capitula in the laboratory). In these cases, the peritrophic membrane was pulled off the midgut and discarded and the epithelium was gently rinsed in sterile water. These operations were intended to minimize the presence of bacteria from the alimentary bolus in these specimens, which had not been fed with sterile solutions. In these cases, the cleaned midgut was used for bacterial DNA extraction but not for microbial culturability tests.

Attempts at cultivation of extraperitrophic bacteria. The possible culturability of the bacteria hosted in the midgut of the insects, across the peritrophic sheath, was verified by plating the extracted midgut tissue on different standard microbiological media. PCA, potato dextrose agar, malt agar, brain heart infusion, McConkey agar, trypticase soy agar, DeMan, Rogosa and Sharpe agar and LuriaBertani agar (all from Oxoid) were used. Only insects that had been surface-sterilized as pupae and reared in microbiologically controlled conditions from that stage onwards were used.

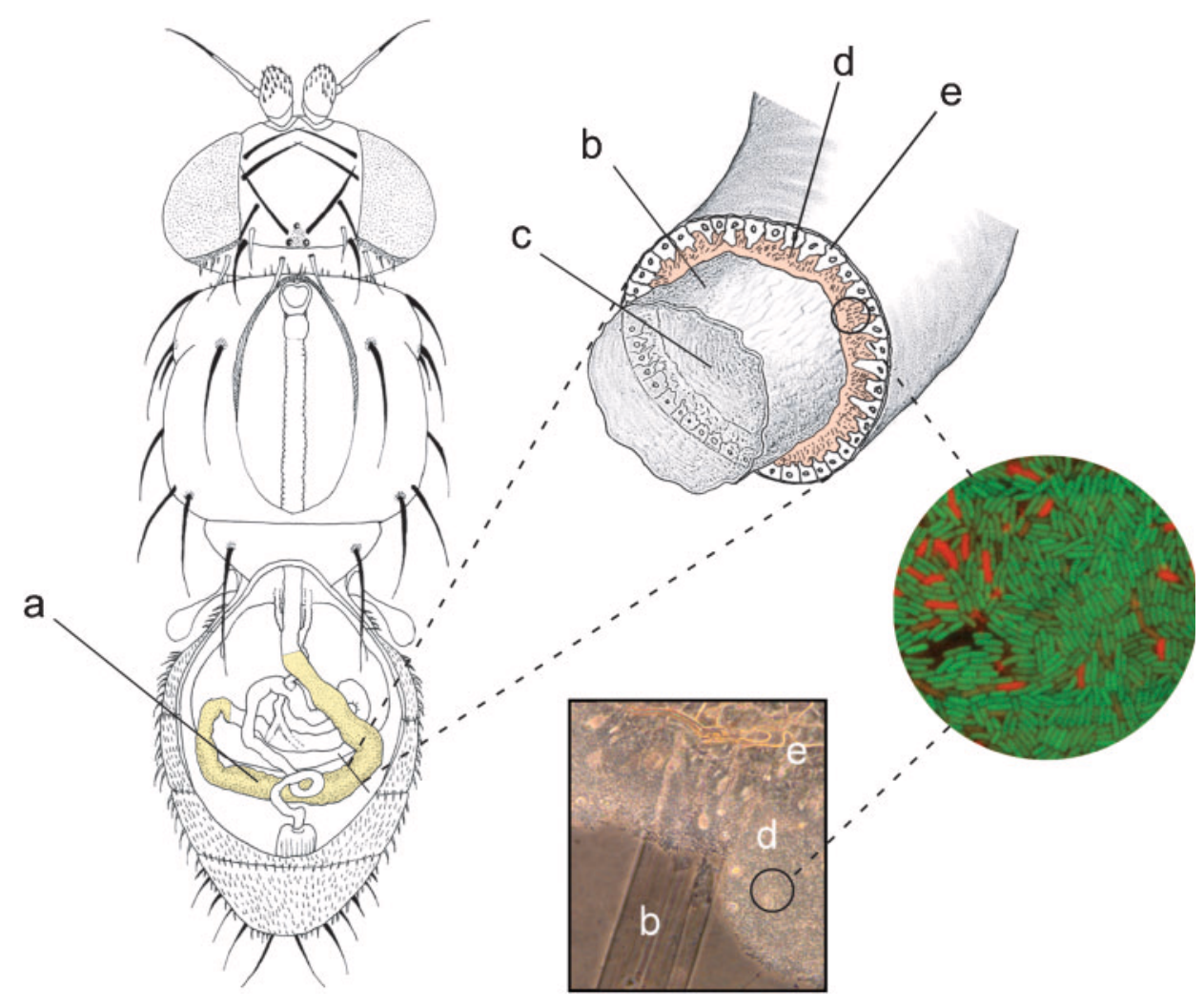

Fig. 2. Anatomical location of symbiotic bacteria in Tephritis matricariae. The drawing, portraying an insect observed under a dissecting microscope, shows the position of the midgut tract in which symbiotic bacteria reside (yellow portion). (a) Close-up detail (right) shows the co-axial presence of an inner thin vessel: the peritrophic membrane (b), in whose lumen (c) regular alimentary bolus transit occurs and many non-specific easily culturable bacteria can be found. Instead, in the interstitial gap space that runs all along $(d)$, between the peritrophic tube and the outer midgut epithelium (e), resident bacteria are observed, which constitute the target of the present analysis. BacLight assays for bacterial cell viability under fluorescent light microscopy; live cells fluoresce green; dead cells fluoresce red. 
In order to verify the actual presence and viability of bacterial cells in the specimens, a section of each midgut used for cultivation attempts was observed under a light microscope and analysed by physiological staining using the LIVE/DEAD BacLight bacterial viability kit (Molecular Probes). Slides were also prepared for Gram staining. Morphological characterization was performed using an Olympus BX60 microscope.

DNA extraction and 16S rRNA gene amplification. The starting material for the molecular taxonomical analysis of the insectassociated prokaryotes was the midgut tract in which bacteria reside between the epithelium and the peritrophic membrane as already described (Fig. 2). The operation was performed on insects that had emerged from surface-sterilized pupae and had been reared aseptically until the adult stage, on those that had reached the imaginal stage from stored freshly harvested flower heads and on adults that had been captured directly in the field (Table 1). DNA was extracted from the content of the midguts as described by Palmano et al. (2000). PCR amplification targeting the $16 \mathrm{~S}$ rRNA gene was carried out in a $25 \mu \mathrm{l}$ volume containing $1 \mu \mathrm{l}$ from the nucleic acid extract, $200 \mu \mathrm{M}$ dNTPs, $0.8 \mu \mathrm{M}$ of each primer, $0.625 \mathrm{U}$ Taq DNA polymerase (Amersham Biosciences) and $2.5 \mu \mathrm{l} 10 \times$ PCR buffer $(500 \mathrm{mM} \mathrm{KCL}, 100 \mathrm{mM}$ Tris/HCl, $\mathrm{pH} 9,15 \mathrm{mM} \mathrm{MgCl}_{2}$ ). The universal bacterial $16 \mathrm{~S}$ rRNA primers used were fD1 (5'-AGAGTTTGATCCTGGCTCAG-3') and rP1 (5'-ACGGTTACCTTGTTACGACTT-3') (Weisburg et al., 1991) to yield an expected amplicon of approximately $1500 \mathrm{bp}$. The cycling program, carried out in an INC PTC-100 thermal controller (MJ Research Inc.), consisted of a $95{ }^{\circ} \mathrm{C} 2$ min step followed by 35 cycles at $96{ }^{\circ} \mathrm{C}$ for $30 \mathrm{~s}, 56{ }^{\circ} \mathrm{C}$ for $30 \mathrm{~s}, 72{ }^{\circ} \mathrm{C}$ for $90 \mathrm{~s}$ and a final extension at $72{ }^{\circ} \mathrm{C}$ for $10 \mathrm{~min}$. The amplified products were separated on a $1 \%$ agarose gel and visualized under UV following staining with ethidium bromide.

DNA sequencing and bioinformatics analyses. The amplification products were analysed by dideoxynucleotide sequencing using primer FL4 (5'-CGGGTGAGTAATGTCTG-3') or FL2 (5'GGAACTGCATTCGAAACTG-3').

Further primers were devised from the sequences obtained in order to walk through the entire $16 \mathrm{~S}$ rRNA gene sequence. PCR products were purified with a QIAquick PCR purification kit (Qiagen) and were used as template for sequencing in an ABI PRISM automatic DNA sequencer (Applied Biosystems). For those species in which PCR amplification of the 16S rRNA gene tract would consistently yield more than a single product, individual bands were extracted from the gels with a QIAquick gel extraction kit (Qiagen)

A BLASTN GenBank analysis of the sequences obtained was run through the NCBI website (http://www.ncbi.nlm.nih.gov/). Sequences were inspected and aligned using MEGA 3.1 (Kumar et al., 2004).

Phylogenetic relationships between sequences were estimated by three methods: (i) maximum-parsimony (MP) using PAUP ${ }^{\star} 4.0 \mathrm{~b} 10$ (Swofford, 2002), (ii) approximate maximum-likelihood (ML) using the PHYML software (Guindon \& Gascuel, 2003) and (iii) Bayesian inference (BI) using MrBayes v3.1 (Huelsenbeck \& Ronquist, 2001).

For MP analysis, best trees were obtained by a full heuristic search using starting trees generated by stepwise addition of sequences $(20$ replicates with a randomized order) and the Tree Bisection Reconnection algorithm. Gaps were considered as a 5th state. Node support was obtained by 100 bootstrap replicates.

For ML analysis, the best-fit model of sequence evolution $(\mathrm{TrN}+\mathrm{I}+\mathrm{G})$ was selected by MODEL TEST v3.06 (Posada \& Crandall, 1998) using Akaike Information Criterion tests (Posada \& Buckley, 2004). The best model found was used for approximate ML, using PHYML, with neighbour-joining (NJ) starting trees and 100 replicates of bootstrap.
For the Bayesian analysis the best-fit model $(\mathrm{GTR}+\mathrm{I}+\mathrm{G})$ was selected by the Akaike criterion using MRMODELTEST v2.1 (Nylander, 2004); gaps were also considered using the binary model implemented in MrBayes v3.1. Analysis started from random trees that were sampled for 3000000 generations with a sampling frequency of 10 . The $50 \%$ majority rule consensus tree and Bayesian posterior probability of support were obtained from 225000 sampled trees.

To verify faster evolution in putative endosymbionts, Relative Rate Tests were carried out by using the Kimura's two-parameter distance implemented in PHYLTEST software version 2.0 (Kumar, 1996).

Sequences with less than $99 \%$ similarity to GenBank database entries were screened for chimeras using the CHIMERA CHECK program of the Ribosomal Database Project II (http://rdp.cme.msu.edu/html/).

\section{RESULTS AND DISCUSSION}

\section{Bacterial presence and location in Tephritinae flies}

Twenty-five different fly species, belonging to eight genera were studied. Ten of these had been considered in Stammer's original survey (Stammer, 1929). A list of the insect taxa analysed, of the 34 plant species from which each was isolated along with the place and time of the collection, is shown in Table 1. As some insect species were found on more than one host, and as we isolated the same fly species from more than one site, a total of 58 combinations of insect-plant-site-year were examined.

The symbionts of the subfamily Tephritinae occupied an extracellular location and were visible in the first part of the abdominal midgut (Fig. 2) in all the analysed Tephritinae (Table 1). The bacteria appeared to be adherent to the intestinal epithelium, as already described by Stammer (1929), but external to the peritrophic membrane and therefore not inside the intestinal lumen in direct contact with the food bolus (Fig. 2). They are consistently found in extracellular placements even when they are hosted inside a specialized evagination of the midgut epithelium, such as in Sphenella marginata (Stammer, 1929). In contrast, in the olive fly (subfamily Dacinae), a major agricultural pest that does not dwell in Asteraceae flowers and which hosts bacteria in its unique oesophageal bulb (Capuzzo et al., 2005), no extra-peritrophic gut symbionts are observed and bacterial masses flow in the intestinal lumen, internal to the peritrophic membrane.

As visible by microscopy, samples from the midgut epithelium yielded bacteria that stained Gram-negative, had a mean length of $2.5 \mu \mathrm{m}$ and often formed chains of several cells. The bacteria isolated from Campiglossa guttella and insects of the genus Noeeta appeared small (1-2 $\mu \mathrm{m})$, were coccoid shaped and did not form chains.

The results observed confirmed the usual presence of bacteria in many species of the subfamily Tephritinae, although the function of this association is not yet fully understood. However, a trophic advantage extending throughout the adult stage can be postulated. In fact, symbionts are found in both male and female adults. 
Therefore, the presence of bacteria does not seem to be exclusively linked to maternal transmission for the sole benefit of larval offspring. On the contrary, they may play an important nutritional role in adult survival as supported by the observation that flies that emerge in the laboratory can live for over a year.

\section{Viability and non-culturability of extraperitrophic bacteria}

When performing the LIVE/DEAD BacLight bacterial viability test on the bacteria adhering to the midgut epithelium, including the specimens reared in microbiologically controlled conditions, the majority of cells stained green, indicating a substantially viable population. However, attempts to culture the bacteria by plating on 8 different microbiological solid media did not yield colonies from any of the host species tested. In the same way, in the majority of the cases, microbial colonies did not develop on the PCA culture medium on the bottom of the vials in which the adults from surface-sterilized pupae were introduced and reared for a week. Besides being a control for the aseptic conditions of the rearing technique, this also indicated the absence of culturable bacteria that were released in the faeces or in other excreta. Similar results were observed when the same methods were used for 'Candidatus Erwinia dacicola' dwelling in the head organ of the olive fly (Capuzzo et al., 2005), suggesting that in these, as in many other bacterial-insect associations, the prokaryotic partner is not yet culturable ex situ on standard microbiological media. In fact, several studies have concluded that a loss of the ability for multiplication outside the host correlates with symbiotic coevolution between insects and bacteria.

\section{Bacterial 16S rRNA gene sequence analysis}

Adults or larvae were used as outlined in Table 1. A total of 86 samples were processed which accounted, on average, for three repetitions from each of the 25 insect species.

After cell lysis, amplification of the small subunit ribosomal gene using eubacterial universal primers and nucleotide sequencing, the results could be aligned and compared.

It is remarkable to report that 17 out of the 25 insect species were found to possess a specific and unique single bacterial symbiont and that three symbiont sequences were found to be shared by two or three insect species. Those insect species that shared an identical symbiont sequence (Tephritis postica-Tephritis hendeliana-Tephritis hyoscyami; Tephritis leontodontis-Tephritis fallax and Trupanea stellata-Capitites ramulosa) are known from insect taxonomy to be very closely related. In addition, there was a nearly complete reproducibility of the results for sequences of the bacteria isolated from the same insect species, i.e. the fulllength 16S rRNA gene sequences (about $1300 \mathrm{bp}$ ) of the bacteria inhabiting a given insect species always turned out to be identical, irrespective of the geographical site of isolation (from the Alps to the central Apennine range), year of collection or of the plant species. The latter distinction applies to oligophagous flies, such as members of the genera Acanthiophilus or Sphenella, in which the same insect species can lay eggs in different plants of the family Asteraceae. For one insect species, Noeeta pupillata, slightly different sequences were observed from flies obtained from three different plant species of the genus Hieracium. This result could, however, also suggest the existence of a complex of sibling species.

The comparison of bacterial sequences in pairwise alignments indicated a range of similarity ranging from a maximum of $99 \%$ (within the genus Tephritis group) to a minimum of $92 \%$ (across the symbiont of Acanthiophilus helianthi and the symbiont group of the genus Noeeta).

A methodological consideration was performed in retrospect. Identical bacterial sequences were obtained from all the species of the subfamily Tephritinae reported (Table 1), irrespective of the rearing history of the individuals. In fact, adults from surface-sterilized pupae hatched in sterile vials or those that emerged in non-sterile conditions, or even wild ones that were occasionally captured, yielded the same PCR product. This indicated that the simple additional procedures of removing the peritrophic membrane and rinsing the midgut could ensure a clean PCR outcome even in a non-gnotobiotic situation, supposedly due to a prevailing amount of the specific putative endosymbiont DNA. As a consequence, rearing in a microbiologically controlled situation is not always necessary and the simplified procedure could be useful for future studies of this kind. A critical issue, however, is to avoid newly hatched adults and to work with those insects which were at least 1 week post-emergence. In the former, there are usually too few bacteria and the PCR may be template-limited. Stammer (1929) noticed that bacteria become abundant and are easily detected in insects about a week post-emergence.

\section{Phylogenetic placement of the symbiotic bacteria}

A BLAST analysis of the sequences revealed the degree of $16 \mathrm{~S}$ rRNA gene sequence similarity with recognized taxa. Results indicated that all of the samples belonged to the family Enterobacteriaceae in the class Gammaproteobacteria. Sequences of the bacterial symbionts from the genera Tephritis, Acanthiophilus, Sphenella, Trupanea and Capitites shared no more than $96 \%$ similarity with database taxa. Instead there were cases for which a similarity level of about $99 \%$ with known culturable species indicated a different relationship; this is the case for the symbiont from Campiglossa guttella with Erwinia persicina (GenBank accession no. AM184098), of that of the symbiont from Dioxyna bidentis with Erwinia persicina (Z96086) and of the symbionts from the Noeeta genus group with Ewingella americana (DQ383802).

Bacterial 16S rRNA gene sequences were subjected to molecular phylogenetic analyses using MP, ML and BI 
methods (Fig. 3). Representative members of the closest known relatives indicated by the BLAST analysis were also included. It was noteworthy that the tree topology of the bacterial symbionts mainly corresponded to the phylogeny of the subfamily Tephritinae based on morphological features.

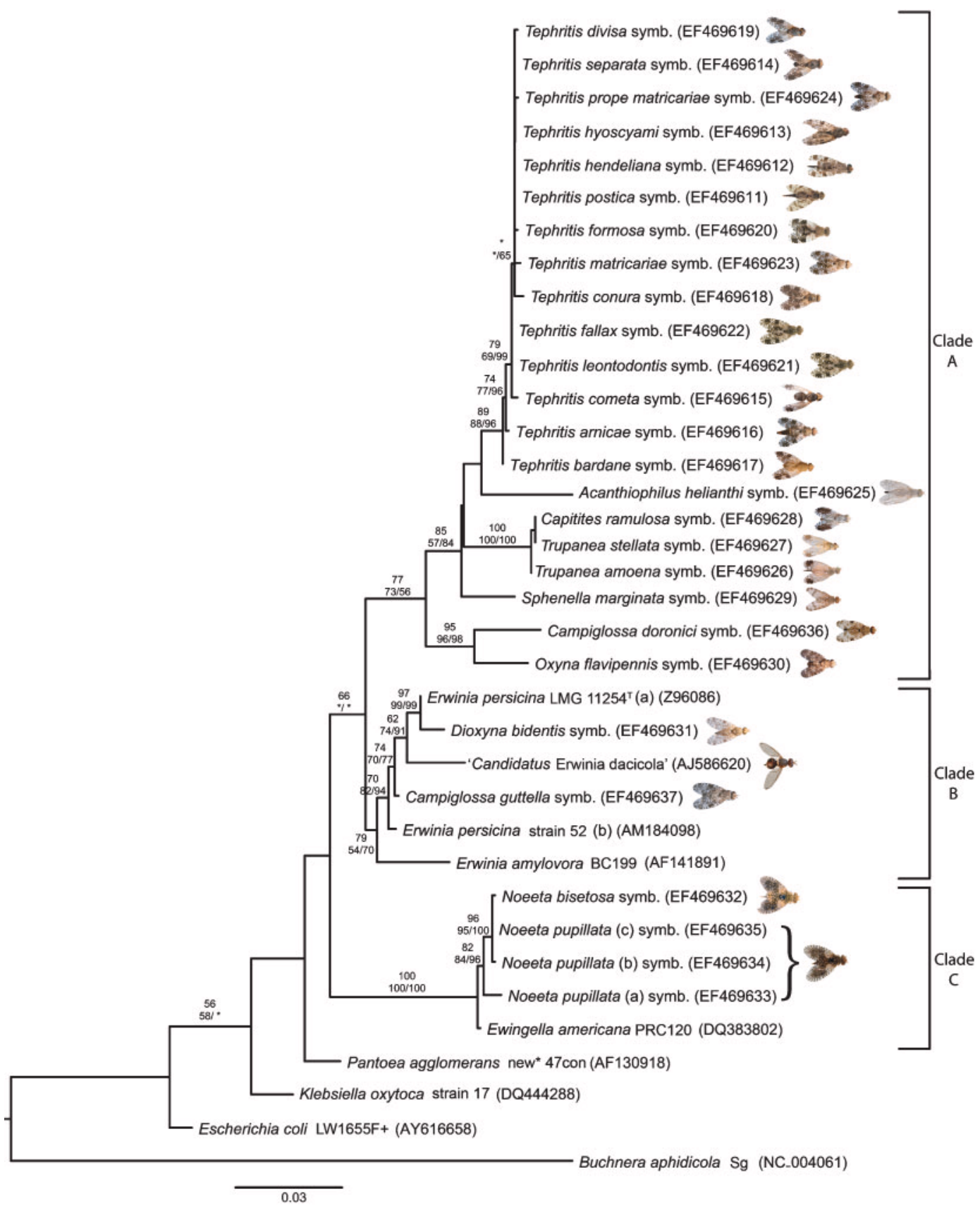

Fig. 3. Phylogenetic tree of bacterial symbionts of the subfamily Tephritinae and close relatives within the class Gammaproteobacteria, based on the 16S rRNA gene sequences, constructed upon the alignment of a minimum common portion of 1324 nucleotides (GenBank accession numbers given in parentheses). The ML tree is shown, with the bootstrap probabilities (ML, MP) and posterior probabilities (BI) reported on the nodes scoring a support higher than $50 \%$ in at least one of the three methods (asterisks indicate bootstrap values lower than $50 \%$ ). Position of the values at nodes: ML: top, MP/BI: bottom. For the three cases in which identical symbiont sequences were found (Tephritis postica-Tephritis hendelianaTephritis hyoscyami; Tephritis leontodontis-Tephritis fallax; and Trupanea stellata-Capitites ramulosa), only one member is listed in the branch. Bar, number of substitutions per site for a unit branch length. 
Three main clades were clearly distinguished and supported by each of the clustering methods used (Fig. 3).

Clade A included symbionts from all the analysed species within the genera Tephritis, Acanthiophilus, Sphenella, Trupanea, Capitites and Oxyna, as well as the symbiont of Campiglossa doronici. None of the other sequences present in GenBank grouped in this clade, suggesting that the symbionts in this group are probably monophyletic. The inference was well supported by the bootstrap values of all three methods used (77\% for ML, $73 \%$ for MP and $56 \%$ for $\mathrm{BI})$. Inside this clade, the taxon assignment of host insects for the genus Tephritis was strongly aligned with the grouping of their symbiotic bacteria (ML $89 \%$, MP $88 \%$ and BI $96 \%)$. The same agreement (100\% ML, $100 \% \mathrm{MP}$ and $100 \% \mathrm{BI}$ ) was seen for the two species of the genus Trupanea, although there was symbiont sequence similarity between Trupanea stellata and Capitites ramulosa. For this clade, the most similar freeliving bacteria belonged to the genus Erwinia, sharing 95$96 \%$ sequence similarity.

Clade B, that grouped together with free-living members of the genus Erwinia, stemmed out as an apparent sister group of clade A. However, the bootstrap value (66\%) given by only one method (ML) suggested a weak affinity. Dioxyna bidentis and Campiglossa guttella symbionts belonged to this clade as well as our previously described 'Candidatus Erwinia dacicola', the olive fly symbiont (Capuzzo et al., 2005), with similarity values ranging from 97 to $99 \%$ with other species of the genus Erwinia.

It is noteworthy that symbionts of the two analysed species of the genus Campiglossa belonged to different clades.

Clade C was statistically well supported (100\% for all three methods) and included symbionts found in all species of the genus Noeeta analysed. The most similar (99\%) free-living culturable species to this group was the human pathogen Ewingella americana. The symbionts of the genus Noeeta appear to have been acquired independently from those of the other members of the subfamily Tephritinae considered in this study. The bacterial symbiosis of the subfamily Tephritinae may therefore be considered not to be monophyletic. In this respect, it is important to recall that the genus Noeeta belongs to the tribe Noeetini, which is phylogenetically well separated (Han et al., 2006) from the tribe Tephritini which includes all of the other species of clades A and B (with the exception of 'Candidatus Erwinia dacicola' which was isolated from one species belonging to the subfamily Dacinae).

The 16S rRNA gene sequences of Klebsiella oxytoca and Pantoea agglomerans, two of the most common fruit flyassociated intestinal bacterial species for the families Trypetinae and Dacinae (Rossiter et al., 1983; Lloyd et al., 1986), did not show particular similarity with any of these three clades.

\section{Rates of evolution and biases of sequence composition}

When bacteria live confined within isolated contexts, a particularly fast rate of DNA sequence evolution is shown to take place. This is presumably due to the absence of recombination with external populations and because of a more pronounced effect of genetic drift (Moran, 1996; Brynnel et al., 1998). Tests to verify whether a differential rate of evolution exists between a putative endosymbiont and its closest culturable free-living relative have been described ( $\mathrm{Wu} \& \mathrm{Li}, 1985$; Muse \& Weir, 1992). The calculation (Relative Rate Test) uses the distance of a third outgroup species and tests the null hypothesis that species $\mathrm{A}$ and $\mathrm{B}$ have evolved at the same rate since divergence. We applied the test to different examples of our putative symbiotic bacteria in comparison with their nearest freeliving neighbours. The results are summarized in Table 2. All the 16S rRNA gene sequences of clade A exhibited a significantly high rate of substitution, ranging from 3.2- to 4.7-fold, when compared with their free-living sister lineage. Higher rates were observed in clade B, with 'Candidatus Erwinia dacicola' and Dioxyna bidentis evolving 6.6- and 8.5-fold more rapidly than the non-symbiont counterpart Erwinia persicina. Relative substitution rates from Campiglossa guttella (clade B) and all Noeeta symbionts (clade $\mathrm{C}$ ) were not significantly different from those of their nearest culturable bacteria.

The test further supports the supposition that the extraperitrophic bacteria of the subfamily Tephritinae, sharing low sequence similarities with free-living species, are bona fide insect symbionts.

In many insect symbioses, including those of species of the genus Buchnera in aphids, the location of the bacterial symbiont is intracellular. In our case, the bacteria occupy an extracellular cavity and are separated from the intestinal lumen only by the thin peritrophic membrane. Thus, the chance of contact with the outer environment is higher than in endocellular symbionts.

A strong $\mathrm{A}+\mathrm{T}$ mutational bias is often observed in the genomes of endosymbionts, supposedly due to a loss of repair genes (Wernegreen, 2002). Buchnera aphidicola has an $\mathrm{A}+\mathrm{T}$ content of $50.6 \%$, while the $\mathrm{A}+\mathrm{T}$ content of Tephritinae symbionts in the $16 \mathrm{~S}$ rRNA gene of Tephritinae symbionts ranges from $44.6 \%$ to $47.2 \%$, values that are not significantly different from the $44.2 \%$ displayed by their free-living relative Erwinia persicina. Other exceptions in this $\mathrm{A}+\mathrm{T}$ richness are observed in symbiont bacteria presumed to have recently established associations with their hosts (Heddi et al., 1998; Baumann et al., 2002; Lefèvre et al., 2004). On the other hand, maintaining traits common to those of culturable freeliving species could be envisaged as not unlikely in some symbioses. In the present case, it has to be stressed that the symbionts (i) are extracellular, (ii) undergo cycles of rapid multiplication in newly emerged adults, and (iii) are exposed to direct contact, and possibly competition, with 
Table 2. Relative rate tests for the $16 \mathrm{~S}$ rRNA gene between taxa of extracellular symbionts of Tephritinae (Taxon 1) and related freeliving bacteria (Taxon 2), with Escherichia coli (AY616658) as third (outgroup) member

\begin{tabular}{|c|c|c|c|c|c|c|}
\hline Tephritis group & E. amylovora & 0.034 & 0.008 & $0.026 \pm 0.0055$ & $4.76^{\star}$ & 4.3 \\
\hline Acanthiophilus helianthi & E. amylovora & 0.044 & 0.009 & $0.034 \pm 0.0065$ & $5.31^{\star}$ & 4.7 \\
\hline Sphenella marginata & E. amylovora & 0.037 & 0.012 & $0.026 \pm 0.0060$ & $4.26^{\star}$ & 3.2 \\
\hline Oxyna flavipennis; Campiglossa doronici & E. amylovora & 0.040 & 0.012 & $0.028 \pm 0.0059$ & $4.80^{\star}$ & 3.4 \\
\hline Dioxyna bidentis & E. persicina (b) & 0.005 & 0.001 & $0.005 \pm 0.0020$ & $2.44^{\star}$ & 8.5 \\
\hline Noeeta group & E. americana & 0.004 & 0.002 & $0.002 \pm 0.0012$ & 1.70 & 2.1 \\
\hline
\end{tabular}

$\dagger$ Tephritid symbionts.

\$Related free-living bacteria: Erwinia amylovora (AF141891); Erwinia persicina (a) (AM184098); Erwinia persicina (b) (Z96086); Ewingella americana (DQ383802).

$\S$ Mean of observed number of substitutions per site in comparison to the common ancestor of Taxon 1 and Taxon 2.

IIDistance difference.

IZ-statistic: Z-values higher than $1.96\left(\right.$ marked with ${ }^{\star}$ ) are requested to reject the rate constancy at the $5 \%$ level (Kumar, 1996).

\#L1/L2.

other bacteria from the gut contents when hosted in the gastric caeca in larval insect stages.

\section{Considerations on the origin of the symbiosis}

A thorough evaluation of the evolutionary relationships between hosts and symbionts will require the expansion of the present analysis in two main directions: (i) investigating the symbionts of species of the subfamily Tephritinae inhabiting other continents, and (ii) carrying out a parallel phylogenetic analysis on the insect hosts by sequencing their rRNA or other genes to verify the congruence of the resulting tree with the one based on bacterial sequences. Regarding hypotheses on the origin of this symbiosis, it appears that at least three distinct events could have taken place. The earliest concerns clade A and possibly involves the putative ancestor of the present representatives of the genus Erwinia. More recent independent events of lateral genetic transfer would instead be supported by the situation observed in the two other clades, in both of which Tephritinae symbionts appear intermingled with free-living members of the family Enterobacteriaceae (Erwinia persicina in clade B and Ewingella americana in clade C) or with symbionts of more distantly related insects (e.g. Bactrocera oleae, belonging to the Dacinae subfamily and hosting 'Candidatus Erwinia dacicola'). For the latter case, we envisage the possibility of an acquisition in relatively recent time, involving the descent of free-living species commonly occurring on vegetation. Other cases of insect-bacteria symbioses of apparently polyphyletic origin, invoking an interpretation based on lateral gene transfer events, are reported in the literature, as for example in the case of the closely related bacteria found in Sitophilus weevils and Glossinia tsetse flies (Lefèvre et al., 2004).

\section{Proposal of 'Candidatus Stammerula tephritidis'}

The phylogenetic analyses delineated above describe three main phenons. For one of these, namely clade A, a deep and robust separation from the other branches exists, and the levels of similarity with known taxa are below $96 \%$. The degree of $16 \mathrm{~S}$ rRNA gene sequence divergence that currently separates different genera within the family Enterobacteriaceae ranges between 2\% and $8 \%$ (Moran et al., 2005). On the basis of these premises, we propose the designation of a candidate genus, 'Candidatus Stammerula, to include symbionts of Tephritinae flies occurring in clade A. Among these, as evidenced from Fig. 3, an extremely coherent subset is represented by the sequences originating from all insects belonging to the genus Tephritis, sharing $99 \%$ gene sequence similarity. We propose that this group is representative of a candidate species under the designation 'Candidatus Stammerula tephritidis'.

Regarding the more variable remaining sequences that also cluster in clade A, encompassing the symbionts from members of the genera Acanthiophilus, Trupanea, Sphenella, Campiglossa and Oxyna, we propose that these be gathered under the same designation and we envisage a possible future assignment either to the candidate genus described above or to new ones once a larger number of insect hosts is investigated in order to refine the rank attribution of their symbionts.

\section{Description of 'Candidatus Stammerula tephritidis'}

Stammerula (Stam.me.ru'la. N.L. fem. n. Stammer in honour of the German biologist Hans-Jurgen Stammer who first described bacteria associated with Tephritinae flies; L. fem. dim. suff - ula; Stammerula named after Hans- 
Jurgen Stammer; tephritidis (teph.ri.ti.dis. N.L. gen. n. tephritidis of the Tephritis, the insect genus with which the bacteria are associated).

[(Enterobacteriaceae) NC; G-; R; NAS (GenBank accession nos EF469611-EF469624); oligonucleotide sequences of unique regions of the 16S rRNA gene specific for the candidate genus are 1109-1123 GGACCTyATyAAAGT; The $y$ at position 1118 is an insertion peculiar to this group of organisms; oligonucleotide sequences of unique regions of the 16S rRNA gene specific for the candidate species are: 5-18 GATGTCGTAAGACC; 86-104 GAGGTAATGGCTTACCTAA; 288-301 GAGGTTAATAACCC. S (Tephritis spp., extracellular space between gut epithelium and peritrophic membrane); M].

Straight rod-shaped cells of $2-3 \mu \mathrm{m}$ (sometimes giving origin to long chains). Negative for Gram staining. Unculturable on microbiological media. Symbiont of Tephritis arnicae, Tephritis bardanae, Tephritis cometa, Tephritis conura, Tephritis divisa, Tephritis fallax, Tephritis formosa, Tephritis hendeliana, Tephritis hyoscyami, Tephritis leontodontis, Tephritis matricariae, Tephritis postica and Tephritis separata (Diptera, Tephritidae). Located exclusively in association with its host species within the following structures: extraperitrophic space of the midgut. Basis of assignment: 16S rRNA gene sequences. $\mathrm{G}+\mathrm{C}$ content of the $16 \mathrm{~S}$ rRNA gene sequence is $54.5 \mathrm{~mol} \%$.

\section{ACKNOWLEDGEMENTS}

We are thankful to Dr B. Merz (Muséum d'Histoire Naturelle, Département d'Entomologie, Genève) for identification and validation of tephritid fly specimens and to Professor U. Ziliotto and Dr L. Marini (Dipartimento di Agronomia Ambientale e Produzioni Vegetali, Università di Padova) for the botanical species. Dr D. Emer and Dr G. Vio is acknowledged for collaborating in fly collection and Dr S. Alberghini for microbiological support. The authors wish to thank DuPont Europe for the unrestricted University Grant on fruit flies symbiosis and Professor M. Costello, of the California Polytechnic State University, for the paper revision.

\section{REFERENCES}

Aksoy, S. (1995). Molecular analysis of the endosymbionts of tsetse flies: $16 \mathrm{~S}$ rDNA locus and over-expression of a chaperonin. Insect Mol Biol 4, 23-29.

Bandi, C., Damiani, G., Magrassi, L., Grigolo, A., Fani, R. \& Sacchi, L. (1994). Flavobacteria as intracellular symbionts in cockroaches. Proc $R$ Soc Lond B Biol Sci 257, 43-48.

Baumann, P. \& Moran, N. A. (1997). Non-cultivable microorganisms from symbiotic associations of insects and other hosts. Antonie van Leeuwenhoek 72, 39-48.

Baumann, P., Lai, C., Baumann, L., Rouhbakhsh, D., Moran, N. A. \& Clark, M. A. (1995). Mutalistic associations of aphid and prokaryotes: biology of the genus Buchnera. Appl Environ Microbiol 61, 1-7.

Baumann, L., Thao, M. L., Hess, J. M., Johnson, M. W. \& Baumann, P. (2002). The genetic properties of the primary endosymbionts of mealybugs differ from those of other endosymbionts of plant sapsucking insects. Appl Environ Microbiol 68, 3198-3205.
Belcari, A. (1985). Presenza di Acanthiophilus helianthi su girasole in Toscana. Inf Fitopatol 35, 23-26.

Brynnel, E. U., Kurland, C. G., Moran, N. A. \& Andersson, S. G. (1998). Evolutionary rates for tuf genes in endosymbionts of aphids. Mol Biol Evol 15, 574-582.

Buchner, P. (1965). Endosymbiosis of Animals with Plant Microorganisms. New York: Interscience Publishers, Inc.

Campbell, B. C., Bragg, T. S. \& Turner, C. E. (1992). Phylogeny of symbiotic bacteria of four weevil species (Coleoptera: Curculionidae) based on analysis of $16 \mathrm{~S}$ ribosomal DNA. Insect Biochem Mol Biol 22, 415-421.

Capuzzo, C., Firrao, G., Mazzon, L., Squartini, A. \& Girolami, V. (2005). 'Candidatus Erwinia dacicola', a coevolved symbiotic bacterium of the olive fly Bactrocera oleae (Gmelin). Int J Syst Evol Microbiol 55, 1641-1647.

Clark, M. A., Baumann, L., Munson, M. A., Baumann, P., Campbell, B. C., Duffus, J. E., Osborne, L. S. \& Moran, N. A. (1992). The eubacterial endosymbionts of whiteflies (Homoptera: Aleyrodoidea) constitute a lineage distinct from the endosymbionts of aphids and mealybugs. Curr Microbiol 25, 119-123.

Foote, R. H., Blanc, F. L. \& Norrbom, A. L. (1993). Handbook of the Fruit Flies (Diptera: Tephritidae) of America North of Mexico. Ithaca, NY: Comstock.

Girolami, V. (1973). Reperti morfo-istologici sulle batteriosimbiosi del Dacus oleae Gmelin e di altri ditteri tripetidi, in natura e negli allevamenti su substrati artificiali. Redia 54, 269-294 (in Italian).

Girolami, V. (1983). Fruit fly symbiosis and adult survival: general aspects. In Fruit Flies of Economic Importance, pp. 74-76. Edited by R. Cavalloro, Rotterdam. Proc CEC/IOBC Int Symp, Athens November 1982.

Guindon, S. \& Gascuel, O. (2003). A simple, fast, and accurate algorithm to estimate large phylogenies by maximum likelihood. Syst Biol 52, 696-704.

Han, H. Y., Ro, K. E. \& McPheron, B. A. (2006). Molecular phylogeny of the subfamily tephritinae (Diptera: Tephritidae) based on mitochondrial $16 \mathrm{~S}$ rDNA sequences. Mol Cells 22, 78-88.

Headrick, D. H. \& Goeden, R. D. (1998). The biology of nonfrugivorous tephritid fruit flies. Annu Rev Entomol 43, 217-241.

Heddi, A., Charles, H., Khatchadourian, C., Bonnot, G. \& Nardon, P. (1998). Molecular characterization of the principal symbiotic bacteria of the weevil Sitophilus oryzae: a peculiar $\mathrm{G}+\mathrm{C}$ content of an endocytobiotic DNA. J Mol Evol 47, 52-61.

Hendel, F. (1927). 49. Trypetidae. In Die Fliegen der Palaearktischen Region. Edited by E. Lindner. Stuttgart, Germany: Schweitzerbart'sche Verlagsbuchhandlung.

Huelsenbeck, J. P. \& Ronquist, F. (2001). MrBayes: Bayesian inference of phylogeny. Bioinformatics 17, 754-755.

Kumar, S. (1996). Phyltest: Phylogenetic Hypothesis Testing Software, version 2.0. University Park, PA: Penn State University.

Kumar, S., Tamura, K. \& Nei, M. (2004). MEGA3: integrated software for molecular evolutionary genetics analysis and sequence alignment. Brief Bioinform 5, 150-163.

Lefèvre, C., Charles, H., Vallier, A., Delobel, B., Farrell, B. \& Heddi, A. (2004). Endosymbiont phylogenesis in the Dryophthoridae weevils: evidence for bacterial replacement. Mol Biol Evol 21, 965-973.

Lloyd, A. C., Drew, R. A. I., Teakle, D. S. \& Hayward, A. C. (1986). Bacteria associated with some Dacus species (Diptera: Tephritidae) and their host fruit in Queensland. Aust J Biol Sci 39, 361-368.

Merz, B. (1994). Diptera: Tephritidae. Insecta Helvetica Fauna, vol. 10. Lausanne: Musée d'Histoire Naturelle de Neuchatel.

Moran, N. A. (1996). Accelerated evolution and Muller's ratchet in endosymbiotic bacteria. Proc Natl Acad Sci U S A 93, 2873-2878. 
Moran, N. A., Russell, J. A., Koga, R. \& Fukatsu, T. (2005). Evolutionary relationships of three new species of enterobacteriaceae living as symbionts of aphids and other insects. Appl Environ Microbiol 71, 3302-3310.

Munson, M. A., Baumann, P. \& Moran, N. A. (1992). Phylogenetic relationships of endosymbionts of mealybugs (Homoptera: Pseudococcidae) based on $16 \mathrm{~S}$ rDNA sequences. Mol Phylogenet Evol 1, 26-30.

Muse, S. V. \& Weir, B. S. (1992). Testing for equality of evolutionary rates. Genetics 132, 269-276.

Noda, H., Nakashima, N. \& Koizumi, M. (1995). Phylogenetic position of yeast-like symbiotes of rice planthoppers based on partial $18 \mathrm{~S}$ rDNA sequences. Insect Biochem Mol Biol 25, 639-646.

Nylander, J. A. A. (2004). MrModeltest v2.1 [computer program]. http://www.ebc.uu.se/systzoo/staff/nylander.html

Palmano, S., Firrao, G. \& Locci, R. (2000). Sequence analysis of domains III and IV of the $23 \mathrm{~S}$ rRNA gene of verticillate streptomycetes. Int J Syst Evol Microbiol 50, 1187-1191.

Petri, L. (1909). Ricerche Sopra i Batteri Intestinali della Mosca Olearia. Roma: Memorie della Regia Stazione di Patologia Vegetale di Roma.

Pignatti, S. (1982). Flora d'Italia. Edagricole, Bologna.

Posada, D. \& Buckley, T. R. (2004). Model selection and model averaging in phylogenetics: advantages of AIC and Bayesian approaches over likelihood ratio tests. Syst Biol 53, 793-808.

Posada, D. \& Crandall, K. A. (1998). MODELTEST: testing the model of DNA substitution. Bioinformatics 14, 817-818.

Ricci, C. \& Ciriciofolo, E. (1983). Osservazioni sull'Acanthiophilus helianthi Rossi (Diptera Tephritidae) dannoso al cartamo in Italia centrale. Redia 66, 577-592.

Rossiter, M. C., Howard, D. J. \& Bush, G. L. (1983). Symbiotic bacteria of Rhagoletis pomonella, pp. 77-82. Edited by R. Cavalloro, Rotterdam. Proc CEC/IOBC Int Symp, Athens November 1982.
Rouhbakhsh, D., Lai, C.-Y., von Dohlen, C. D., Baumann, L., Baumann, P., Moran, N. A. \& Voegtlin, D. J. (1996). The tryptophan biosynthetic pathway of aphid endosymbionts (Buchnera): genetics and evolution of plasmid-associated $\operatorname{trp} E G$ within the Aphididae. $J$ Mol Evol 42, 414-421.

Schröder, D., Deppisch, H., Obermayer, M., Krohne, G., Stackebrandt, E., Hölldobler, B., Goebel, W. \& Gross, R. (1996). Intracellular endosymbiotic bacteria of Camponotus species (carpenter ants): systematics, evolution and ultrastructural analysis. Mol Microbiol 21, 479-489.

Séguy, E. (1934). Diptères (Brachycères) (Muscidae Acalypterae et Scatophagidae), vol. 28. Paris: Faune de France.

Stammer, H. J. (1929). Die bakteriensymbiose der trypetiden (Diptera). Zoomorphology 15, 481-523.

Swofford, D. L. (2002). PAUP*: Phylogenetic analysis using parsimony (and other methods), version 4. Sunderland, MA: Sinauer Associates.

Weisburg, W. G., Barns, S. M., Pelletier, D. E. A. \& Lane, D. J. (1991). 16S Ribosomal DNA amplification for phylogenetic study. J Bacteriol 173, 697-703.

Wernegreen, J. J. (2002). Genome evolution in bacterial endosymbionts of insects. Nat Rev Genet 3, 850-861.

White, I. M. (1988). Tephritid Flies Diptera: Tephritidae. Handbook for the Identification of British Insects, vol. 10, Part 5a. London: Royal Entomological Society of London.

Wu, C. I. \& Li, W. H. (1985). Evidence for higher rates of nucleotide substitution in rodents than in man. Proc Natl Acad Sci U S A 82, 1741-1745.

Zwölfer, H. (1983). Life systems and strategies of resource exploitation in tephritids. In Fruit Flies of Economic Importance, pp. 16-30. Edited by R. Cavalloro. Rotterdam. Proc CEC/IOBC Int Symp, Athens November 1982 